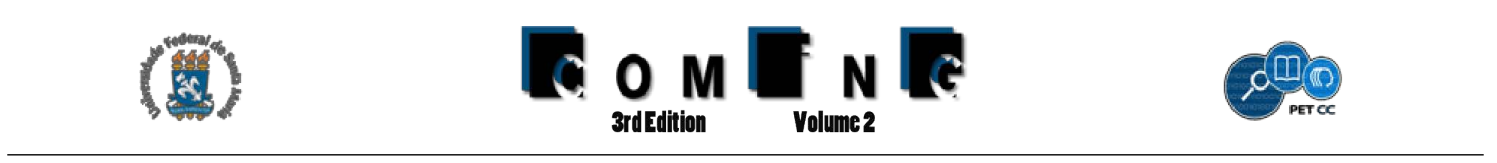

\title{
Café com Especialista e Conexão Sistemas: PET-SI promovendo discussão e diálogo entre alunos, professores e profissionais da Informática
}

\author{
Anthony Tailer Ribas de Almeida ${ }^{1}$, Camila da Luz Nogueira ${ }^{1}$, Cássio Castro Araujo ${ }^{1}$, \\ Franciel Augusto Hass Krein ${ }^{1}$, Iago Cunha Corrêa ${ }^{1}$, Leonardo Henrique Steil ${ }^{1}$, \\ Lucas Lima de Oliveira ${ }^{1}$, Rhauani Weber Aita Fazul ${ }^{1}$, \\ Romeu Isaac Casarotto ${ }^{1}$, Patrícia Pitthan Barcelos ${ }^{1}$ \\ ${ }^{1}$ Centro de Tecnologia - Universidade Federal de Santa Maria (UFSM) \\ Santa Maria - RS - Brazil \\ \{aalmeida, cnogueira, caraujo, fkrein, icorrea, lsteil, loliveira, \\ rwfazul, rcasarotto, pitthan\}einf.ufsm.br
}

\begin{abstract}
The Tutorial Education Program, within the courses where it is present, aims to qualify the students formation through education, research and extension activities. Especially in the computer area, new technologies, researches and topics to be addressed frequently arise. Therefore it is essential that the group finds with the academic community ways to adapt to this changes and to know what is, in fact, happening in the area. Some specific activities promoted by the group aim essentially the adaptation of the professional formed by the course through debates and informal conversations with professionals of the sector.
\end{abstract}

Resumo. O Programa de Educação Tutorial dentro dos cursos em que está inserido visa qualificar a formação dos alunos através de atividades de ensino, pesquisa e extensão. Especialmente na área da Computação, frequentemente surgem novas tecnologias, pesquisas e assuntos a serem abordados. Portanto, é essencial que o grupo encontre, junto à comunidade acadêmica, formas de se adaptar a essas mudanças e conhecer o que de fato está acontecendo na área. Algumas atividades específicas promovidas pelo grupo visam essencialmente as questões de adaptação dos profissionais que serão formados pelo curso através de debates e conversas informais com profissionais do meio.

\section{Introdução}

O Programa de Educação Tutorial (PET), criado e oferecido pelo Ministério da Educação (MEC) desde 2005, é formado por alunos sob a tutoria de um docente, sendo executado a nível de ensino superior nas instituições de todo o país. O programa é mantido por seus integrantes seguindo as diretrizes indissociáveis da tríade ensino, pesquisa e extensão.

As atividades promovidas pelos grupos do Programa de Educação Tutorial buscam uma colaboração entre os todos alunos dos cursos em que estão inseridos. A Educação Tutorial é centrada no desenvolvimento do pensamento crítico e de habilidades de resolução de problemas através da aprendizagem por meio da vivência, reflexões e discussões em 
Café com Especialista e Conexão Sistemas: PET-SI promovendo discussão e diálogo ComInG entre alunos, professores e profissionais da Informática

clima de cooperação. Com atividades de ensino, pesquisa e extensão o grupo oferece atividades tanto para a comunidade acadêmica quanto para a comunidade regional externa a instituição. Levar o grupo para fora da Universidade é extremamente necessário, pois além de permitir aos alunos adquirirem novas experiências, proporciona à comunidade externa a oportunidade de obtenção de novos conhecimentos.

O intercâmbio de ideias entre os alunos favorece a troca e a negociação, estimulando assim o uso da argumentação. Neste sentido, voltando-se para o curso, o PET-SI desenvolve atividades que contribuem para a elevação da qualidade da formação acadêmica dos alunos de graduação em Sistemas da Informação (SI) da UFSM.

Este artigo tem como objetivo apresentar duas das atividades promovidas pelo grupo PET-SI com foco em proporcionar discussão: "Café com Especialista" e "Conexão Sistemas". Essas atividades, além de promoverem discussões sobre os mais diversos temas, estimulam o espírito crítico dos alunos, trazendo experiências exteriores a academia, que por vezes acaba por nos manter em um pensamento limitado às tarefas que executamos com o intuito de cumprir nosso dever acadêmico. Ambas as atividades citadas proporcionam, não apenas um espaço para os graduandos do curso de Sistemas de Informação se expressarem, como também são abertas aos professores das áreas relacionadas com o curso, estimulando que a interatividade entre alunos e professores aconteça de maneira mais informal, desmistificando o paradigma de que lugar de professor e aluno é apenas dentro da sala de aula.

O artigo encontra-se organizado da seguinte forma: a seção 2 descreve as principais motivações do grupo em proporcionar momentos de discussão entre alunos, professores e profissionais da área; as seções 3 e 4 descrevem as duas atividades promovidas pelo grupo PET-SI focadas em discussão e debates, a saber: "Café com Especialista" e "Conexão Sistemas"; a seção 5 apresenta como é realizada a avaliação pós atividade; e a seção 6 apresenta as considerações finais sobre o trabalho.

\section{Motivação para discussões}

Um curso de computação como Sistemas de Informação busca formar um profissional apto a estar a frente de seu tempo, tendo ideias, contato com profissionais de várias áreas, e demais conhecimentos e experiências que permeiam a interatividade com pessoas em geral, possíveis clientes, parceiros ou mesmo concorrentes. Infelizmente os graduandos da computação em geral possuem um perfil por vezes mais fechado em relação ao compartilhamento de ideias e opiniões, sendo este exatamente o ponto que tentamos atingir com as atividades do grupo. Para isso procuramos oferecer oportunidades para que o graduando tenha um espaço em que possa interagir, expor suas opiniões, debater ideias, estimular o senso crítico, estabelecer contatos e, o mais importante, fazer da vida acadêmica mais do que uma obrigação por um diploma.

As discussões promovidas pelo grupo PET estimulam os graduandos de SI a debaterem entre si sobre a atual realidade do curso. Tal processo, além de explanar o cotidiano vivenciado pelos estudantes, ainda promove a manifestação de diferentes pontos de vista sobre determinados assuntos. Isso, por sua vez, leva os graduandos a um embate de vivências que envolvem desde dificuldades enfrentadas em disciplinas específicas até, por exemplo, problemas burocráticos com matrículas. Nesse sentido, as discussões enriquecem o curso, uma vez que os pontos positivos explanados nos debates podem ser 
Café com Especialista e Conexão Sistemas: PET-SI promovendo discussão e diálogo ComInG entre alunos, professores e profissionais da Informática

potencializados e os pontos negativos, corrigidos.

Nas duas seções seguintes, iremos detalhar melhor o funcionamento de cada uma das atividades tratadas no presente artigo, detalhando de maneira mais clara as metodologias usadas para o desenvolvimento das mesmas.

\section{Atividade Café com Especialista}

No decorrer do curso, a grande maioria dos alunos de SI apresenta uma certa dificuldade para definir a ramificação da área de trabalho que deseja seguir. Com a atividade Café com Especialista, o aluno expande seus conhecimentos sobre a área do profissional convidado que se dispõe a compartilhar suas experiências profissionais com os discentes.

A atividade também pode demonstrar áreas desconhecidas por parte de alguns alunos e, de certa forma, expandir os conhecimentos dos mesmos sobre o curso, podendo inclusive conquistar futuros profissionais que, até então, não tinham definido suas escolhas quanto a área de atuação a seguir.

\subsection{Objetivos e Metodologia}

A Atividade "Café com especialista" consiste em encontros semestrais, em forma de entrevista, para discutir sobre temas relevantes ao curso. A atividade conta com profissionais convidados, os quais estão vinculados a área de Tecnologia da Informação e áreas afins.

Primeiramente é feito um levantamento pelos membros do grupo sobre possíveis palestrantes e, após isso, para escolha do tema da atividade, é discutido qual assunto pode ser de maior interesse por parte dos graduandos de Sistemas de Informação. A partir daí, o palestrante é convidado, e caso demonstre interesse, uma data é marcada para a próxima edição.

O objetivo da atividade é fomentar o interesse dos alunos para as mais variadas áreas da informática, buscando prestar esclarecimentos sobre determinado assunto em específico, a fim de auxiliar e motivar participantes em suas futuras escolhas profissionais.

As discussões propostas na atividade proporcionam aos alunos conhecimentos sobre as mais diversas possibilidades do mercado de trabalho. Neste contexto, o aluno consegue visualizar perspectivas que vão além de sua formação no curso de graduação, pois a atividade também promove a troca de experiências entre entrevistados e participantes, estimulando o intercâmbio de ideias.

$\mathrm{Na}$ área da Tecnologia da Informação as tecnologias utilizadas no mercado de trabalho se encontram em constante evolução. Novas ferramentas e formas de trabalhar surgem na medida em que a demanda dos clientes também se transforma. Essa mudança contínua afeta negativamente os graduandos de informática pois, levando em consideração que os mesmos encontram-se, na maioria das vezes, focados em suas esferas estudantis, lhes falta tempo para acompanhar o que acontece na parte externa à sua realidade universitária. Tendo isso em mente, a atividade objetiva levar aos graduandos o conhecimento hodierno desses profissionais, para que, então, o choque inicial do graduado em SI ao iniciar no mercado de trabalho possa ser, de certa forma, minimizado.

Através da atividade, assuntos como ferramentas e linguagens de programação mais utilizadas, boas práticas de programação e processos de desenvolvimento de software são trazidos aos graduandos pelos profissionais convidados para contextualizá-los 
Café com Especialista e Conexão Sistemas: PET-SI promovendo discussão e diálogo ComInG entre alunos, professores e profissionais da Informática

sobre o que está acontecendo fora do âmbito da sala de aula. Essas informações instigam o autodidatismo do aluno para buscar um conhecimento mais aprofundado do que foi trazido à atividade, com objetivo de entender melhor o funcionamento do mercado, levando-o assim, a se tornar um profissional mais qualificado e competente ao concluir seu curso.

A atividade segue uma abordagem totalmente informal, sendo conduzida sob a forma de conversas e debates entre os entrevistadores e entrevistados, havendo, como o próprio nome sugere, a disponibilidade de café para os participantes.

\subsection{Edições Realizadas}

Esta atividade tem sido proposta pelo grupo desde 2014. Sua primeira edição teve como convidado um profissional da área da engenharia elétrica (Figura 1), sendo este diretor de inovação de uma conceituada startup de Santa Maria. A atividade teve seu foco em questões empreendedoras e na vida acadêmica em si, falando sobre as dificuldades e o sucesso na carreira profissional.

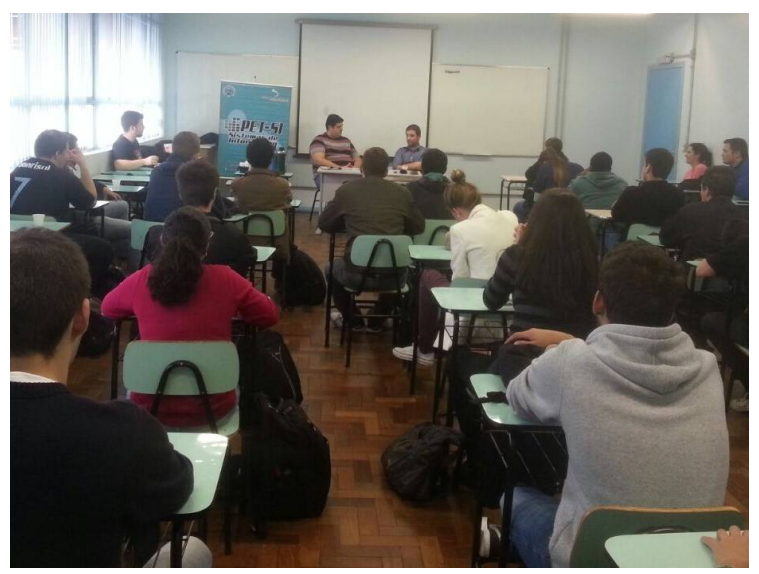

Figura 1. Primeira Edição do Café com Especialista(2014)

A edição seguinte, realizada no segundo semestre de 2015, teve como convidado um profissional da área de Tecnologia da Informação que atuava como diretor comercial e coordenador da governança de duas empresas da região. A atividade enfocou oportunidades e possibilidades de crescimento na área de TI.

Em 2016 foi realizada uma edição (Figura 2) cujo convidado pertence a uma empresa atuante na área de delivery online. Conversamos muito sobre as origens da empresa, o mercado aquecido e os desafios na conquista de novos clientes. Como tudo é muito novo nos negócios eletrônicos, ainda existe muito a aprender, tanto por parte das empresas quanto por parte dos clientes. Foi um momento muito proveitoso e construtivo. Como a Universidade Federal de Santa Maria, além de um lugar de estudos, é também um polo de inovação tecnológica, o grupo PET-SI tem possibilidade de se comunicar facilmente com as já mencionadas startups locais.

\subsection{Contribuições da Atividade}

Dentre as contribuições desta atividade para os alunos destacam-se a interatividade entre o profissional convidado e os alunos do curso de Sistemas de Informação participantes 
Café com Especialista e Conexão Sistemas: PET-SI promovendo discussão e diálogo ComInG entre alunos, professores e profissionais da Informática

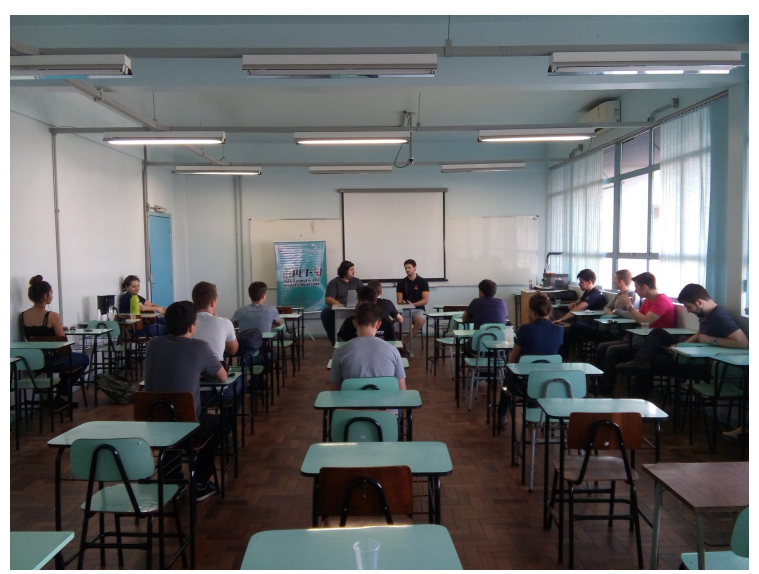

Figura 2. Café com Especialista(2016)

do encontro e a elucidação de possíveis dúvidas que o aluno possa vir a apresentar ao longo de sua graduação quanto à vida profissional de pessoas que atuam na área de Tecnologia da Informação e áreas afins. Para o grupo PET, a atividade otimiza os seguintes aspectos: capacidade de organização, trabalho em equipe e expressão oral, além de agregar conhecimento promovendo saberes para a formação complementar dos integrantes do PET-SI.

Ao fim da atividade, todos os participantes podem ampliar sua rede de contatos, possibilitando a criação de novas relações extra curriculares que serão úteis para, por exemplo, estágios ou experiências profissionais na área da tecnologia da informação. Além disso, os participantes terão uma gama de exemplos reais de profissionais que tornaram-se professores mestres ou doutores e, também, empreendedores que fizeram de sua ideia um serviço ou produto tornando-o seu principal negócio. As discussões e debates com empreendedores também servem para mostrar aos participantes como as inúmeras dificuldades podem vir a se tornar experiências valiosas para as empresas. Todas essas experiências são capazes de incentivar os alunos a tentarem e se arriscarem no mercado de trabalho, pois mostram que são necessários erros e tropeços até que o sucesso seja alcançado e que nenhum especialista tornou-se o que é hoje da noite para o dia.

\section{Atividade Conexão Sistemas}

A Atividade Conexão Sistemas visa principalmente a aproximação de alunos, professores e coordenação em busca de um curso de graduação de excelência. Esta atividade tem como benefícios fomentar a articulação entre alunos, professores e coordenação com o Projeto Pedagógico do Curso de Sistemas de Informação. Através desta atividade é possível estabelecer e discutir metodologias que permitam o desenvolvimento do pensamento crítico e reflexivo dos alunos através das atividades propostas pelo, já citado, Projeto Pedagógico do Curso de Sistemas de Informação.

Nessa atividade não existe um tema fixo, pois são discutidos muitos assuntos pertinentes ao curso de Sistemas de Informação. Logo, no decorrer da atividade, os alunos propõem debates sobre o que acham relevante e assim é dada continuidade ao evento. $\mathrm{Na}$ seguinte seção, serão abordados os objetivos e a metodologia da mesma. 
Café com Especialista e Conexão Sistemas: PET-SI promovendo discussão e diálogo ComInG entre alunos, professores e profissionais da Informática

\subsection{Objetivos e Metodologia}

A Atividade Conexão Sistemas tem por objetivo organizar encontros entre alunos, coordenação e professores, de forma a discutir, avaliar e planejar as atividades a serem realizadas no âmbito do curso de Sistemas de Informação da UFSM. Dentro da tríade, ensino, pesquisa e extensão, a atividade Conexão Sistemas se encaixa, principalmente, no eixo ensino, pois promove debates e discussões visando uma melhoria na qualidade do cenário educacional em que o curso de Sistemas de Informação está inserido.

A Atividade foi criada em 2011 e, inicialmente, cada edição foi desenvolvida em apenas uma etapa, a qual contava com a presença dos professores, coordenação e alunos do curso de Sistemas de Informação. A partir de 2014, cada edição da atividade passou a ser desenvolvida em duas etapas, a primeira delas, realizada no primeiro semestre do ano, envolvendo apenas os alunos do curso e segunda, realizada no semestre seguinte, contando também com a presença dos professores e da coordenação do curso de Sistemas de Informação.

A divisão da atividade em duas etapas possibilita, em um primeiro momento, uma discussão centrada nas opiniões dos alunos do curso, onde podem ser debatidas, de forma mais livre, opiniões, críticas, elogios e sugestões quanto a situação atual em que se encontra o curso de Sistemas de Informação da UFSM. Por fim, na segunda etapa, alunos, professores e coordenação de curso encontram-se para discutir e avaliar as ideias e planejar possíveis soluções para as situações levantadas na primeira etapa.

Assim como o Café com Especialista, a atividade Conexão Sistemas segue uma abordagem informal, sendo conduzida sob a forma de discussões sobre temas propostos pelo grupo PET-SI e sugeridos pelos próprios alunos do curso. Dentre os temas propostos encontram-se melhorias na grade curricular do curso, com ideias sobre uma possível reforma curricular, participação dos alunos nas atividades oferecidas pelo PET, infraestrutura das salas de aula e laboratórios, problemas e sugestões relacionados às atividades complementares de graduação (ACGs) e às disciplinas complementares de graduação (DCGs), metodologia de ensino dos professores, atuação da coordenação em vigência, dentre outros.

\subsection{Edições Realizadas}

Esta atividade, sendo realizada em duas etapas, tem sido proposta pelo grupo desde 2014. Sua primeira edição iniciou a discussão acerca da reforma curricular, que está em debate até hoje, além de ter sido centrada em questões de infraestrutura do Centro de Tecnologia, laboratórios e salas de aula. Em resposta, a coordenação da época informou que estava agindo para aprimorar as questões levantadas e foram discutidas novas ideias e sugestões.

Na primeira etapa da edição de 2015, foram debatidos temas referentes à grade curricular do curso, metodologia dos professores, situação do Diretório Acadêmico de Informática (DAINF), disciplinas e atividades complementares de graduação e a participação de alunos do curso em atividades do PET Sistemas de Informação. Tais questões foram levadas à coordenação de curso, que retornou sua posição na segunda etapa da atividade. Esta etapa também contou com a apresentação do novo coordenador do curso de Sistemas de Informação (Figura 3), além de serem discutidos os problemas da época, como a falta de um secretário na coordenação do curso. 
Café com Especialista e Conexão Sistemas: PET-SI promovendo discussão e diálogo ComInG entre alunos, professores e profissionais da Informática

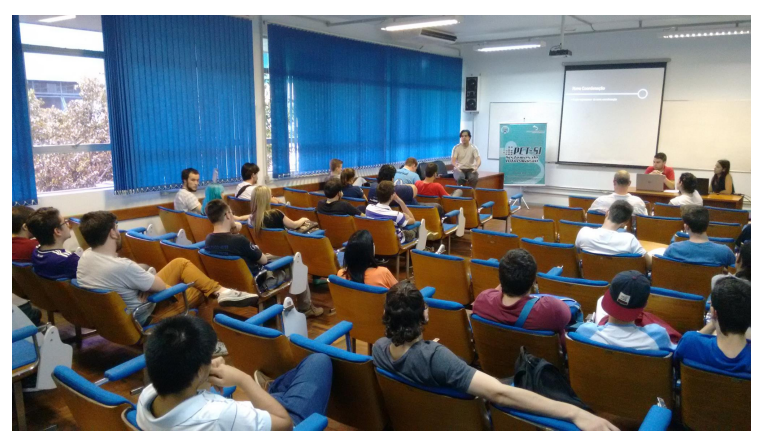

Figura 3. Segunda Etapa da Atividade Conexão Sistemas (2015)

Na edição de 2016, a primeira etapa (Figura 4) se deu em torno de assuntos sobre a nova coordenação do curso, fazendo uma avaliação em relação ao semestre anterior, já que houve, conforme citado anteriormente, troca de coordenadores durante esse período. Outro destaque da atividade foi a divulgação da reativação Diretório Acadêmico da Informática (DAINF), que representa os cursos de Ciência da Computação e Sistemas de Informação, e estava inativo desde 2014. Uma organização entre alunos e PETs de ambos os cursos fez com que o Diretório voltasse a nova formação, através de eleição, e retornasse a ser participativo na vida acadêmica.

Por fim, a segunda etapa da atividade, realizada no segundo semestre de 2016, foi focada na resposta da coordenação do curso sobre os assuntos levantados nas edições anteriores. Alguns assuntos foram resolvidos, como por exemplo a falta de secretário na coordenação e outros estão sendo avaliados e discutidos, tais como a reforma curricular do curso de Sistemas de Informação.

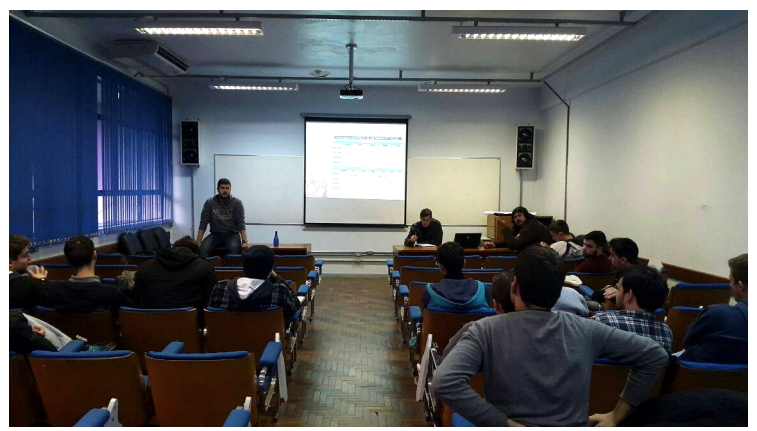

Figura 4. Primeira Etapa da Atividade Conexão Sistemas (2016)

\subsection{Contribuições da Atividade}

Dentre as contribuições dessa atividade, destacam-se a interação entre os membros do grupo PET-SI com os demais alunos do curso de Sistemas de Informação, de modo a viabilizar o efeito multiplicador do PET sobre a comunidade acadêmica. Além disso, a atividade tem como objetivos estimular o comprometimento com o Projeto Pedagógico do Curso e com sua proposta curricular, estabelecer novas metodologias de ensino através das atividades propostas pelo Projeto Pedagógico do Curso e promover o bolsista a agente multiplicador do conhecimento, de cidadania e de novas práticas de ensino/aprendizagem junto ao Curso de Sistemas de Informação. 
Café com Especialista e Conexão Sistemas: PET-SI promovendo discussão e diálogo ComInG entre alunos, professores e profissionais da Informática

Após a realização da atividade, todas as ideias, sugestões e críticas são levadas às partes competentes, para que as mesmas possam oferecer respostas e soluções às questões levantadas. Pelo fato da atividade, como citado anteriormente, ser dividida em duas etapas por ano, todos os relatos pertinentes surgidos dos alunos na primeira etapa da atividade são levados à coordenação do curso. Assim, na segunda etapa, a coordenação de curso pode dar seu posicionamento, resolvendo alguns dos pontos levantados. Questões mais complexas que possam vir a demandar mais tempo, são acompanhadas tanto pela coordenação quanto pelo PET, para que num futuro, alternativas e soluções possam ser levadas aos alunos do curso de Sistemas de Informação.

\section{Avaliação Final das Atividades}

$\mathrm{Na}$ atividade Café com o Especialista, o grupo PET-SI se reúne para debater os acontecimentos ocorridos no evento. Primeiramente é discutido a qualidade da apresentação do tema e da conversação, no que tange o especialista que conduziu o evento. Para tal, são discutidas ideias sobre a aceitação do tema pela comunidade acadêmica e pelo público em geral. Após isso, é avaliado pelos integrantes do grupo se o tema apresentado na respectiva atividade conseguiu ser suficientemente atrativo para, quem sabe, poder ser utilizado em atividades futuras. A definição de aceitação do tema é feita após avaliação do quórum e também de feedbacks dos alunos participantes da atividade.

O convidado, por sua vez, também pode sugerir mudanças para a melhoria da atividade, no que diz respeito, por exemplo, a infraestrutura disponível no momento da atividade, divulgação, público, dentre outros. Com as opiniões sobre o evento de ambas as partes, tanto do público quanto do especialista, o grupo PET-SI pode avaliar a atividade como um todo, discutindo pontos a serem mantidos e pontos a serem melhorados.

Em contrapartida, para avaliar a atividade Conexão Sistemas, é averiguado se houve uma participação satisfatória da comunidade acadêmica em conjunto com a coordenação do curso. A presença da comunidade é sempre de extrema importância, pois é devido as suas discussões que os problemas referentes ao curso de Sistemas de Informação são colocados em foco, possibilitando assim as devidas melhorias e soluções.

Além disso, é verificado se os pontos discutidos foram ou não atendidos e averiguado se os problemas levantados na atividade foram solucionados de forma adequada. A posição da coordenação do curso nestas questões e a avaliação que parte dos próprios alunos, possibilita uma avaliação abrangente sobre as possíveis melhorias na vida acadêmica que a atividade ajudou a proporcionar.

\section{Considerações Finais}

$\mathrm{O}$ artigo apresentou duas atividades conduzidas pelo grupo PET Sistemas de Informação cujo enfoque concentra-se na discussão de ideias. A atividade Café com Especialista apresenta uma nova prática pedagógica, que prioriza a interatividade e vai muito além da introdução de conhecimento. Por essa atividade ser um encontro com um especialista ou empreendedor de alguma área da informática, a troca de informações acrescenta aos alunos do curso um conhecimento que por vezes não seria obtido em sala de aula, despertando assim, a curiosidade e interesse de cada participante. Pode- se considerar que esta atividade presta grande auxílio aos alunos na hora de direcionar sua formação através das disciplinas complementares ou projetos de pesquisa, como também com a decisão de que 
Café com Especialista e Conexão Sistemas: PET-SI promovendo discussão e diálogo ComInG entre alunos, professores e profissionais da Informática

área da computação seguir depois de concluir a graduação, sendo na área acadêmica ou no mercado de trabalho como profissional ou empreendedor.

Da mesma forma que a atividade Café com Especialista, a atividade Conexão Sistemas proporciona discussões e debates, visando estabelecer e discutir metodologias que permitam o desenvolvimento do pensamento crítico e reflexivo dos alunos. Outra similaridade entre as atividades refere-se à informalidade com a qual as atividades são conduzidas. A atividade Conexão Sistemas promove uma maior aproximação entre alunos, professores e coordenação de curso em busca de um curso de graduação de qualidade. Adicionalmente a atividade faz com que discentes e docentes discutam e analisem o Projeto Pedagógico do Curso de Sistemas de Informação, subsidiando órgãos como Colegiado do Curso e Núcleo Docente Estruturante (NDE).

Estabelecer um diálogo e criar uma conexão entre alunos, professores e profissionais da área faz destas atividades um canal de comunicação, abrindo portas para novas ideias e otimizações tanto no curso de Sistemas de Informação, quanto na carreira dos alunos. Isso mostra à comunidade acadêmica que a Universidade não é apenas um ambiente de estudo, mas também um ambiente para partilhar experiências e opiniões. Ao proporcionar esses momentos para conversas informais entre estudantes e profissionais, estimula-se uma cultura de inovação, fazendo com que essa cooperação entre os envolvidos transforme ideias em resultados além de possibilitar o surgimento de novos produtos e/ou pesquisas de qualidade que poderão formar profissionais diferenciados.

Pensando além da formação de cada aluno, esses diálogos viabilizam um aprimoramento do curso de Sistemas de Informação como um todo, aumentando sua visibilidade dentro e fora da instituição, o que pode ocasionar no aumento do interesse de estudantes externos pelo curso.

\section{Referências}

MEC (2016). Ministério da Educação - Ministério da Educação. http://portal.mec.gov.br/.

PET-SI (2016). PET - Sistemas de Informação — Site do grupo PET-SI da Universidade Federal de Santa Maria. http://ufsm.br/pet-si.

PORTAL-MEC (2016). Diretrizes Curriculares Nacionais para os cursos de bacharelado e licenciatura em Computação. IEEE Cloud Computing.

SBC (2015). Currículo de Referência da SBC para Cursos de Graduação em Bacharelado em Ciência da Computação e Engenharia de Computação. https://goo.gl/5Y8LPB,.

SI-UFSM (2016). Sistemas de Informação - Informática UFSM. http://www.inf.ufsm.br/index/graduacao/graduacao/si/graduacao.

UFSM, I. (2013). Estrutura do Curso - Informática UFSM. http://www.inf.ufsm.br/index/graduacao/si/estrutura-do-curso. 